\title{
A narrativa visual do álbum F. Matarazzo \& Cia Industriaes, 1904-1906
}

\section{The visual narrative of the F. Matarazzo \& Cia Industriaes album, 1904-1906}

\section{Elisa Pomari}

\section{Resumo}

O álbum F. Matarazzo \& Cia Industriaes foi idealizado pelo grupo F. Matarazzo \& Cia e produzido pelo fotógrafo Orestes Cilento, entre 1904 e 1906, momento de transformação das atividades do grupo, que trouxe a necessidade de divulgação dos negócios. A obra, durante muito tempo a única a retratar sistematicamente o interior das fábricas, é uma narrativa visual inserida num contexto de produção, circulação e consumo de imagens fotográficas como prática de grandes empresas. Tais imagens colaboraram para o fortalecimento dessas empresas, ao mesmo tempo em que contribuíram para a formação de grandes personalidades empresariais míticas. Assim, o artigo analisa o discurso dessas fotografias em torno da produção, da aparência do ambiente fabril e das relações de trabalho ali desenvolvidas.

Palavras-chave: Fotografia; Matarazzo; Industrialização; São Paulo (Estado) - Indústrias.

\section{Abstract}

The F. Matarazzo \& Cia Industriaes photographic album was commissioned by the group to the photographer Orestes Cilento and produced between the years 1904 and 1906, a moment of transformation in the activities of the group and that brought the need to divulge the business. The work, for a long time the only one to systematically portray the interior of the factories, is a visual narrative inserted in a context of production, circulation and consumption of photographic images as a business practice of large companies. These images collaborated for the strengthening of the companies while contributing to the formation of great mythical business personalities. Thus, the article analyzes the discourse of these photographs around the production, the appearance of the factory environment and the labor relations developed there.

Keywords: Photography; Matarazzo; Industrialization; São Paulo (State) - Industries.

* Graduada em História pela Universidade Estadual de Campinas. Mestra em História na área de Política, Memória e Cidade pela mesma instituição. Atualmente desenvolve pesquisa de doutorado na linha Cultura Visual, História Intelectual e Patrimônios do Programa de Pós Graduação em História da Universidade Estadual de Campinas (IFCH/ Unicamp). E-mail: pomari. elisa@gmail.com 


\section{Dossiê}
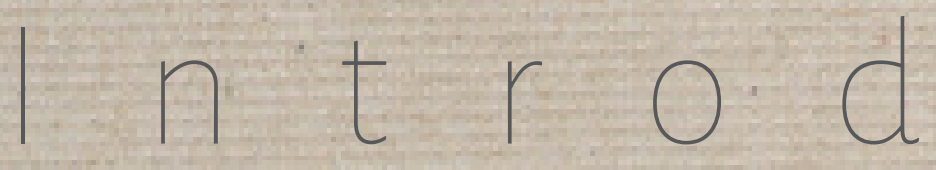

U

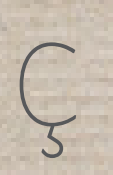

$\tilde{a}$

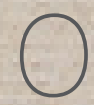

$\mathrm{O}$

bjetos visuais de diferentes formatos, com variadas temáticas e contextos de produção foram importantes artefatos e agentes na construção de discursos e relações sociais, econômicas, políticas e culturais (CELL, 1998). No cenário oitocentista de surgimento e difusão de inovações técnico-científicas, que permitiram a construção de dispositivos mecânicos e impulsionaram rápidas transformações, a fotografia surgiu como possibilidade técnica e rapidamente consolidou-se como objeto de consumo, prática social e fenômeno estético. Em poucas décadas as imagens fotográficas, em suas múltiplas formas, inundaram o cotidiano e o imaginário de diversas sociedades.

Em um regime visual no qual a ilusão, a subjetividade, a efemeridade e o fascínio do espetáculo eram valorizados ${ }^{1}$, as imagens fotográficas colaboraram para a consolidação de tradições de representação e, somando ao seu potencial de comunicação, a facilidade de circulação e a velocidade de recepção pelos observadores, foram importantes vetores de ideias e discursos. Participaram da construção de narrativas, da disciplinarização do olhar, da atenção (CRARY, 2012) e do efeito de naturalização de práticas, paisagens e dinâmicas sociais que emergiam. Assim, dialogaram e contribuíram com projetos de sociedade que tentavam se estabelecer.

Em meio ao processo de expansão e consolidação do sistema fabril, a produção e publicação de imagens fotográficas tornou-se uma importante ferramența de comunicação, apropriada por diversos atores sociais individuais e coletivos, a partir da qual foram elaboradas narrativas visuais sobre o cotidiano das fábricas, os trabalhadores, o processo de modernização econômica e a industrialização como um todo. Os industriais foram grandes fomentadores da produção de fotografias, criadas para circulações específicas dentro e fora de seus empreendimentos, incluindo tanto as imagens elaboradas de e para comemorações internas, como a documentação de seus negócios e atividades com fins publicitários ou para atração de potenciais investimentos. Neste segundo caso enquadra-se o álbum F. Matarazzo \& Cia Industriaes.

1 Os termos apresentados são recorrentes em análises clássicas sobre fenômenos das sociedades que passaram pela experiência da consolidação de novas formas de produção e de significativo aumento na circulação de mercadorias, especialmente no século XIX e início do século XX. Ver Benjamin (2007), Debord (1997), Hardman (1991) Barbuy (1999). 
A análise aqui apresentada foi baseada nas reflexões da historiadora Ana Maria Mauad (2008), que concebe a fotografia como um processo histórico e social de construção de sentido e propõe sua observação a partir de aspectos históricos e estruturais da imagem. ${ }^{2}$ Portanto, para sua leitura e interpretação devem ser observados dados técnicos, que dizem respeito às formas de expressão das imagens fotográficas, tais como quem a produziu, seu tamanho, suporte, enquadramento, foco, iluminação; e seus aspectos de conteúdo, dentre os quais local, tema, existência de pessoas e objetos etc. A partir da decomposição das informações presentes na superfície visível, Mauad propõe o estabelecimento de diversos espaços discursivos na imagem: espaço fotográfico, espaço geográfico, espaço do objeto, espaço de figuração e espaço de vivência. Para a autora, "os campos espaciais permitem o restabelecimento de códigos de representação social e de comportamento, no seu marco de historicidade" (MAUAD, 2008, p. 46). Trata-se, assim, de esmiuçar o que está visível na imagem fotográfica para compreendê-la como produtora e produto de relações de sentido específicas, ou seja, históricas.

Isto posto, o artigo retoma a narrativa visual do álbum idealizado pelo grupo F. Matarazzo \& Cia e realizado pelo fotógrafo Orestes Cilento, entre 1904 e 1906, inserindo-o num contexto de produção, circulação e consumo de imagens fotográficas como uma prática de grandes empresas, que colaboraram para seu fortalecimento, ao mesmo tempo em que contribuíram para a formação de grandes personalidades empresariais míticas. Além disso, essas fotografias foram, por muito tempo, as únicas a retratarem sistematicamente o interior das fábricas, motivo pelo qual têm uma grande força discursiva em torno de sua aparência e das relações ali desenvolvidas.

\section{F. Matarazzo \& Cia}

Apesar de não ser o único proprietário dos negócios ou o único de sua família a conquistar poder econômico, relevância política e prestígio social, Francisco foi, sem dúvida, o principal responsável por tornar notável o sobrenome Matarazzo, motivo pelo qual emprestou seu nome ao grupo e ao álbum. Os rumores e mitologias sobre sua vida antes da emigração para o Brasil, entre o fim 1880 e o início de 1881, assim como as motivações de sua vinda são inúmeras. Contudo, pode-se dizer com certa segurança que sua família não apenas não era pobre como era

2 A autora também considera os apontamentos de Meneses (2003) e constrói uma proposta de análise das imagens a partir de quatro ângulos: da produção (sujeito e aparato técnico); da recepção (as condições históricas de observação e relacionamento com outras imagens); do produto (da materialidade da imagem e seu potencial narrativo); e do agenciamento (a dimensão de artefato da imagem, sua biografia). 
bastante proeminente em sua cidade de origem, Castellabate, localizada na região campana de Cilento, província de Salerno, no sul da Itália. É igualmente possível afirmar que, em meio à reorganização estrutural e fiscal iniciada pelo processo de unificação - desastrosa especialmente para parte dos proprietários do sul -, os tempos eram difíceis e a família havia enfrentado desafios financeiros que impulsionaram a viagem do filho mais velho para outro continente. Mas ele não veio desprovido de amparo na travessia, tinha contato de um conterrâneo bem estabelecido na região de Sorocaba, no interior paulista, um carregamento de banha - que na maioria das versões da história teria sido perdido no desembarque - além de capital, elementos que lhe garantiram segurança (DEAN, 1971; MARTINS, 1973; COUTO, 2004). Embora, para o olhar em retrospecto, já como fundador de um dos maiores complexos industriais do continente, pudesse parecer um início humilde, estes pertences iniciais certamente o diferenciaram da maior parte dos italianos que aqui chegaram e foram fundamentais para seu sucesso econômico.

Matarazzo fixou-se inicialmente em Sorocaba, onde deu início às suas atividades como comerciante de secos e molhados. Em 1882 abriu um armazém, no fundo do qual começou, junto com sua mulher, Filomena, a fabricação de banha de porco para venda no próprio estabelecimento, visto que a consumida aqui era importada e a criação de suínos era considerável naquela região. Rapidamente expandiu a produção para duas outras fábricas em áreas próximas. Este período foi classificado por José de Souza Martins (1973, p. 43) como a fase de comércio rural, na qual a fabricação de banha era atividade secundária. Em seguida viria a fase do comércio ampliado e da importação. Assim, nos anos iniciais da República, mudou-se para a Capital; associou-se e desassociou-se dos irmãos em três empresas diferentes, provavelmente para a capitalização das empresas, em meio à política econômica do Encilhamento; firmou uma casa comercial na rua 25 de março, que se tornou atacadista; e, por fim, uma importadora, na qual era associado ao irmão André (Andrea). Após um vultoso financiamento do London $\delta$ Brazilian Bank, a F. Matarazzo \& Cia deixou de ter como principal atividade a importação de farinha norte-americana e tornou-se proprietária do único moinho do estado de São Paulo em 1889, o Moinho Matarazzo. A migração para o ramo industrial foi tão lucrativa que, em apenas um ano, o moinho dobrou seu maquinário e capacidade de produção. Desse momento em diante e de maneira muito veloz, multiplicaram-se os negócios industriais: em 1901 ou 1904², foi fundada a Fiação e Tecelagem Mariângela; em 1902, a oficina do moinho foi transformada numa metalúrgica que fabricava lataria para venda de seus produtos. Foi também o período de início da fabricação de óleo para uso doméstico a partir do caroço de algodão e, em 1906, veio a inauguração da fábrica de fósforos. Além disso, nos primeiros anos do século XX. Francisco

3 José Martins aponta dúvida entre as datas de 1901 ou 1904, Ronaldo Costa Couto considera o ano de 1901 como o de fundação. 
Matarazzo participou da fundação de bancos ítalo-brasileiros e recebeu da coroa italiana o título de comendador.

\section{Oálbum}

O álbum F. Matarazzo \& Cia Industriaes começou a ser elaborado em um momento de migração das atividades da companhia. Sua produção, desenvolvida entre os anos de 1904 e 1906, deu-se possivelmente como uma catalogação fotográfica das novas e diversas fábricas. Posteriormente, a obra foi direcionada para a Secretaria da Agricultura Comércio e Obras Públicas do Estado de São Paulo e, assim como o restante do acervo da Secretaria, atualmente compõe uma coleção homônima pertencente à documentação fotográfica do Centro de Memória - Unicamp:

O álbum possui dimensões de um grandioso projeto: $25 \mathrm{~cm} \times 30 \mathrm{~cm} \times 15 \mathrm{~cm}$. Era composto de 100 fotos - das quais uma se perdeu - e tem autoria do estúdio Photo Cilento, de Orestes Cilento, que, segundo o verbete do Dicionário Histórico Fotográfico (KOSSOY, 2002), era: "um dos estabelecimentos tradicionais dentre os fotógrafos de origem italiana no princípio do século XX". Para além do fato de ter se dedicado a retratar a comunidade italiana e ser o autor das fotografias do álbum /l Brasile e gli Italiani-publicado em 1906 pelo jornal Fanfulla, representante da colônia italiana de São Paulo -, não se sabe muito mais sobre o fotógrafo, mas é relevante destacar que seu sobrenome, mais do que de origem italiana, fazia referência à região de onde era proveniente, Cilento, sul da Campânia. Ou seja, Cilento e os Matarazzo, vindos de uma Itália, há pouco unificada e de forte regionalismo, eram efetivamente conterrâneos, assim como muitos outros que trabalharam para o industrial.

F. Matarazzo \& Cia Industriaes traz, nesta ordem, uma foto de Francisco Matarazzo, cuja legenda aponta seu título de comendador, e uma do escritório central do grupo, na rua XV de Novembro; depois, apresenta séries de fotografias dos negócios: Moinho Matarazzo, Fiação e Tecelagem Mariangela, Fábrica de Óleo Sol Levante, Fábrica de Banha A Paulista, Fábrica de Phosphoros Sol Levante; e, porúltimo, da frota de carroças usadas para o transporte das mercadorias, nas quais é possível observar o nome do moinho. Todas as páginas trazem, no topo, a indicação da fábrica à qual se referem e, no rodapé, legendas em português, italiano, francês e inglês.

Para cada uma das fábricas a sequência das imagens foi organizada de maneira bastante similar. As primeiras fotos são vistas externas da fachada ou da entrada. Estas imagens foram registradas, em geral, a partir de locais distantes - mais altos ou mais baixos -, que permitiram a 
captura de planos gerais da maior parte do edifício, possibilitando ver a dimensão dos prédios, assim como elementos de importância para a distribuição da produção, como a proximidade de linhas férreas. As fotos seguintes dedicam-se aos equipamentos e infraestrutura nas fábricas, maquinário, motores, oficina, bombas hidráulicas e equipamento contra incêndio. São seguidas, por fim, das imagens do "pessoal", dos trabalhadores organizados e divididos, dependendo do tamanho do empreendimento, em função, especialização, gênero etc. Dessa forma a própria ordem das fotografias cria a sensação de uma narrativa que busca apresentar, por completo, não apenas os negócios do grupo - indo da administração à distribuição das mercadorias, passando por sua produção -, como também as atividades de cada uma das fábricas. O observador as "vê" por fora, adentra no espaço de produção, onde pode observar o número e a grandiosidade do maquinário e, por fim, ver os trabalhadores que dele se ocupam.

O álbum ainda é acompanhado de um encarte explicativo bilíngue (português/italiano) produzido pela Thypographia Cardozo Filho \& Motta. Ambos trazem adornos e fonte que oscilam entre o art nouveau e o art deco, estilos ligados à indústria e ao discurso da modernidade, reforçando a inserção da publicação em um discurso do moderno. Conforme observado por Vânia Carvalho e Solange Lima (1997, p. 411):

Esses atributos ornamentais garantem a necessária familiaridade com os temas tratados ao facilitar a apreensão visual por integrarem um repertório imagético que abarca desde a ornamentação arquitetônica de fachadas, portões e gradis de ferro, papéis de parede e pintura decorativa parietal, até aquela praticada no campo das artes gráficas [...] Assim os modernos editores narram o moderno da cidade em um invólucro igualmente moderno, consonante com o partido visual dos demais produtos do mercado no qual a sua publicação disputa espaço e leitores. Os invólucros ornamentais buscam, assim, garantir a necessária empatia com o público leitor.

Imagem 1-Detalhe da página 11 do folheto que acompanha o álbum (entre 1904 e 1906)

F. MATARAZZO \& COMP. - INDUSTRIAES

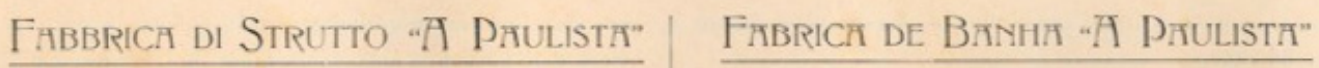
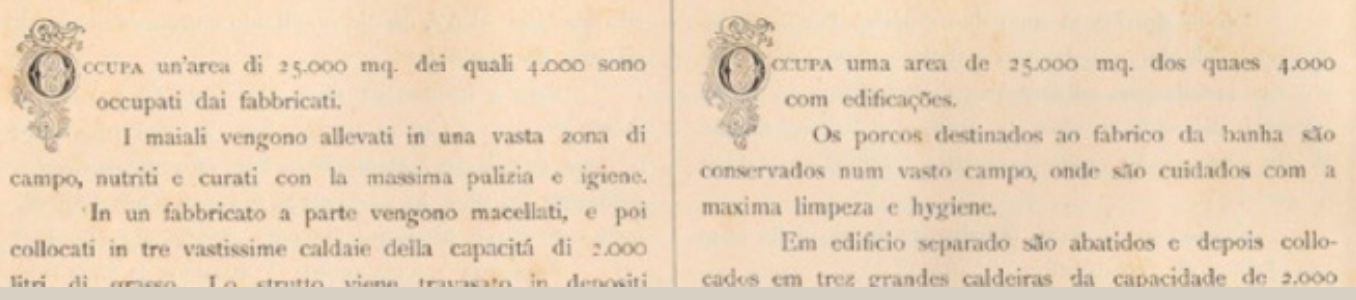

Fonte: Coleção Secretaria da Agricultura Comércio e Obras Públicas do Estado de São Paulo - Centro de Memória-Unicamp 
No encarte também é possível encontrar a descrição de cada uma das fábricas, com detalhes da construção e principalmente do funcionamento das máquinas, sua quantidade, tamanho, capacidade, potência, consumo de energia, produção média e número de funcionários. Dessa forma, o álbum e o folheto somados tornam-se uma visita detalhada às propriedades da $F$. Matarazzo \& Cia, cujo objetivo era mostrar a capacidade de produção, divulgar o investimento tecnológico na aquisição do maquinário, a sua potência, assim como a organização racional do espaço fabril.

Ao considerar suas dimensões, pode-se concluir que o álbum não deve ter sido feito para uma circulação muito ampla. Trata-se de uma apresentação provavelmente destinada a autoridades e figuras importantes no âmbito nacional e internacional, o que lhe confere uma função importante nos negócios da empresa. Ademais, pode-se considerá-lo um meio moderno de divulgação e propaganda da modernidade das empreitadas lideradas por Francisco Matarazzo.

Conforme já apontado, a publicação foi produzida em um momento bastante emblemático para os negócios dos Matarazzo. Segundo Martins, do ponto de vista organizacional, correspondeu ao período em que foi dissolvida a sociedade com os irmãos José (Giuseppe) e Luís (Luigi), cujas fábricas foram readquiridas pela nova associação, F. Matarazzo \& Cia, em sociedade com o irmão André, na qual, embora outros membros da família possuíssem ações, não tinham participação na diretoria. Assim, o álbum pode carregar ainda a função de divulgação do nome do grupo em meio à formação de diversas associações na família.

Além disso, na perspectiva da atividade econômica, corresponde ao início da fase de retomada e grande investimento na atividade industrial, depois de um processo de concentração no comércio importador, com a mudança para São Paulo. O moinho de farinha de trigo, inaugurado em 1900, representou um deslocamento dos negócios no sentido da indústria, ainda que as ações comerciais tivessem sido mantidas, visto que a diversidade de atividades, industriais e comerciais, possibilitava a segurança dos negócios em relação às oscilações econômicas. Logo, pode-se observar uma concentração de imagens, ou seja, um esforço em destacar algumas atividades da empresa - como indicada pelo próprio nome industriaes -, e, de forma mais precisa, algumas das fábricas.

Das 99 fotografias, 26 retratam o Moinho Matarazzo, suas atividades e maquinário. O moinho foi a primeira e a mais rentável das atividades industriais de Matarazzo no início de sua trajetória. Também foi responsável por originar a Fiação e Tecelagem Mariângela -à qual 25 imagens foram dedicadas -, fábrica que posteriormente superou o moinho e a partir da qual se desenvolveu a Fábrica de Óleo Sol Levante, dedicada à extração do óleo do caroço do algodão utili- 
zado na fiação e que conta com um total de 19 fotos. Portanto, mais de dois terços do álbum concentram-se nessas três fábricas recém-criadas. O volume destas imagens relaciona-se à importância financeira que cada empreendimento tinha para a organização e sua ordem indica o processo de desdobramento das atividades: das necessidades de ensacamento do moinho surgiu a fiação, assim como surgiria também, alguns anos depois, uma metalúrgica, a partir da oficina mecânica retratada no álbum. Das sobras da produção de tecidos, teve origem a fábrica de óleo de semente de algodão, principal óleo utilizado para consumo doméstico no período, cujo processo de desodorização era exclusivamente realizado pela F. Matarazzo \& Cia. Dessa forma, também é possível observar na documentação o processo de criação de novas fábricas como uma maneira de responder às necessidades da própria produção industrial. Esse processo, conhecido como concentração vertical, foi característico do período inicial da industrialização e típico dessa fase dos negócios do grupo, pois trazia vantagens fiscais e eliminava dificuldades de abastecimento.

Apesar de ser o mais antigo dos negócios de Matarazzo, as imagens relativas à Fábrica de Banha A Paulista são poucas, apenas sete, e são apresentadas ao leitor somente depois dos novos empreendimentos da capital. Essas imagens já destoam das demais por serem as únicas não localizadas na cidade de São Paulo, mas sim em Capão Bonito, município da região de Itapetininga. Além disso, retratam um empreendimento que era consideravelmente menor em pessoal, maquinário e modernidade industrial do que os demais. Por último, é retratada a Fábrica de Phosphoros Sol Levante, o mais recente empreendimento do grupo. Datado de 1906, aparece ainda em estágio de finalização da construção, mas conta com 17 fotografias. É provável que essas fotografias tenham sido adicionadas com a publicação já em andamento, o que explicaria porque, a despeito do tamanho e maquinários, é a última. Apesar do volume do investimento, esse foi o único estabelecimento liquidado pelo grupo, vendido à Fiat Lux no final da década, segundo Ronaldo Costa Couto (2004, p. 290), precisamente pela impossibilidade de verticalização dos negócios.

\section{As narrativas fotográficas}

A observação das imagens permite, para além de demarcar a hierarquia entre os empreendimentos, remontar os espaços de trabalho e sua provável organização, a ordem da produção e a lógica de funcionamento fabril, por meio do posicionamento das máquinas, da sequência das imagens de uma mesma fábrica e de diversos outros indícios nelas capturados. 
No caso da Fiação e Tecelagem Mariângela, as fotografias têm a seguinte ordem: imagens de abridores e batedores, processos de tratamento do fruto do algodão; cardas e passadores, processos de tratamento da fibra; urdideiras, carretéis, salas de fiação, maçaroqueira, novamente cardas, engomação do fio e remitição, processos de fiação; teares, processo de fabricação do tecido; e, por fim, descascadores. Embora o processo de fiação encontre-se retratado de maneira quase direta, as imagens dos descascadores dos caroços de algodão, que são a primeira etapa do processo, aparecem por último, dentre as máquinas. Fato este que pode ser atribuído à própria organização física do edifício, ou seja, podem ter sido representados na mesma ordem em que os espaços se colocavam para quem entrava na fábrica. O que, no entanto, não impede a reconstituição da lógica e das técnicas de produção.

Além disso, também é possível observar os espaços ocupados pelos trabalhadores. Embora na maioria das fotografias do interior das fábricas os trabalhadores não estejam presentes, podese imaginar sua colocação pela própria localização dos maquinários no espaço, assím como pelo posicionamento das lâmpadas.

Imagem 2-Moinho Matarazzo - Deposito de pano para saccos, machinas de costura e estamparia (entre 1904 e 1906)

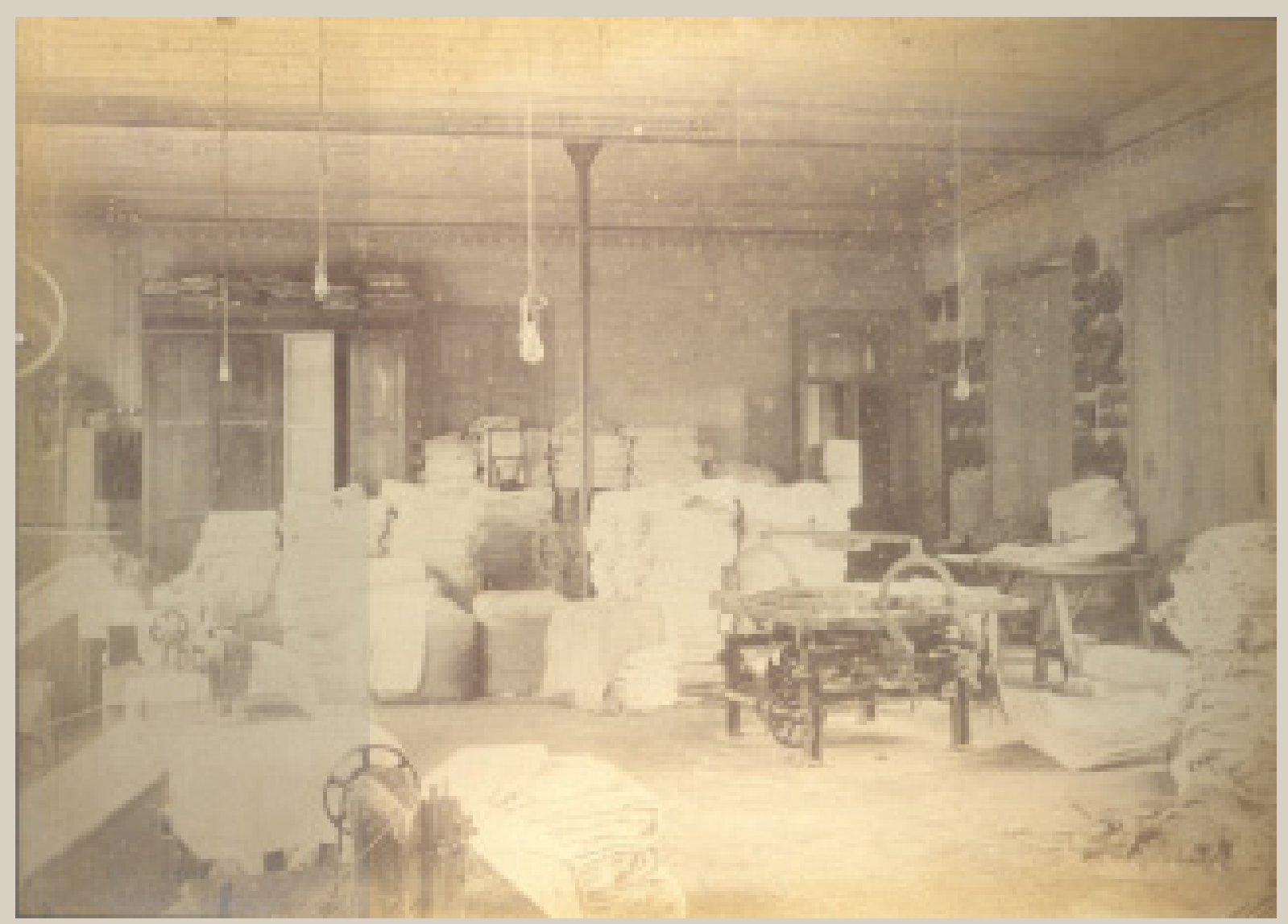

Fonte: Coleção Secretaria da Agricultura Comércio e Obras Públicas do Estado de São Paulo - Centro de Memória-Unicamp 


\section{Dossiê}

Os espaços retratados no álbum estão limpos em quase todas as fotos, dado fantasioso para certos locais que sabidamente envolviam grande quantidade de resíduos, pela lida com separação de grãos, sementes, fibras e fiação. Inclusive, de acordo com boletins do Departamento Estadual de Trabalho, esses eram locais que mereciam atenção por parte dos industriais pela ameaça à saúde que representavam aos trabalhadores. As imagens seguintes, do Moinho Matarazzo e da Fiação e Tecelagem Mariângela - duas das quais retratam os espaços menos limpos presentes no álbum -, são exemplos disso. Nelas é possível observar um asseio pouco provável em meio ao processo de produção. Até mesmo na fotografia do descascador, máquina que separa a fibra da semente do algodão, quase não há produtos ou subprodutos do processo.

Imagem 3-Moinho Matarazzo - Moinho de arroz: Peneiras e separadores de arroz (entre 1904 e 1906)

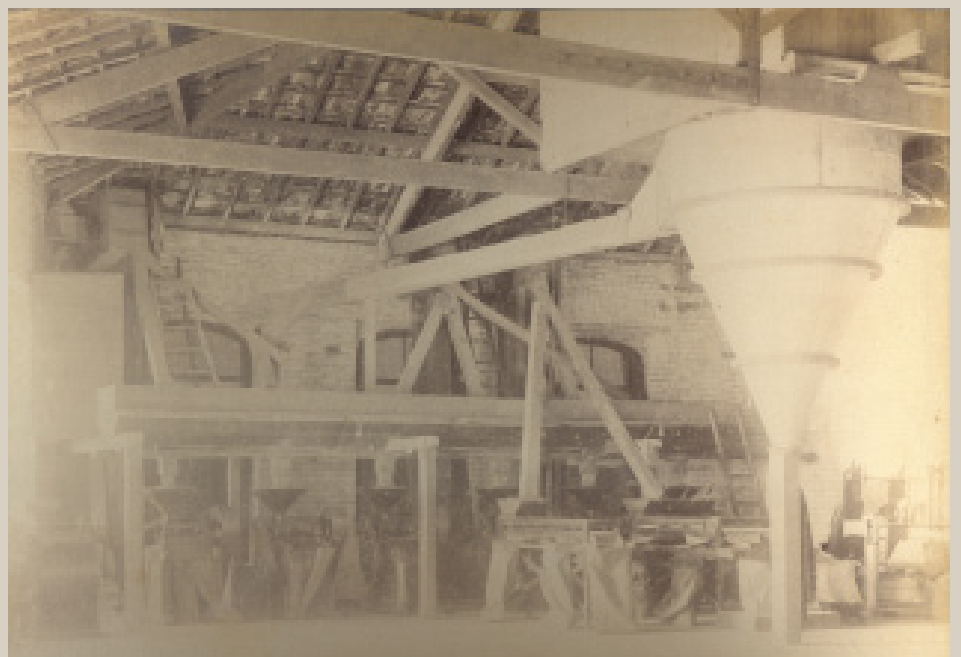

Fonte: Coleção Secretaria da Agricultura Comércio e Obras Públicas do Estado de São Paulo - Centro de Memória-Unicamp

Imagem 4-Fiação e Tecelagem “Mariangela"-Sala Northrop 3a sala (entre 1904 e 1906)

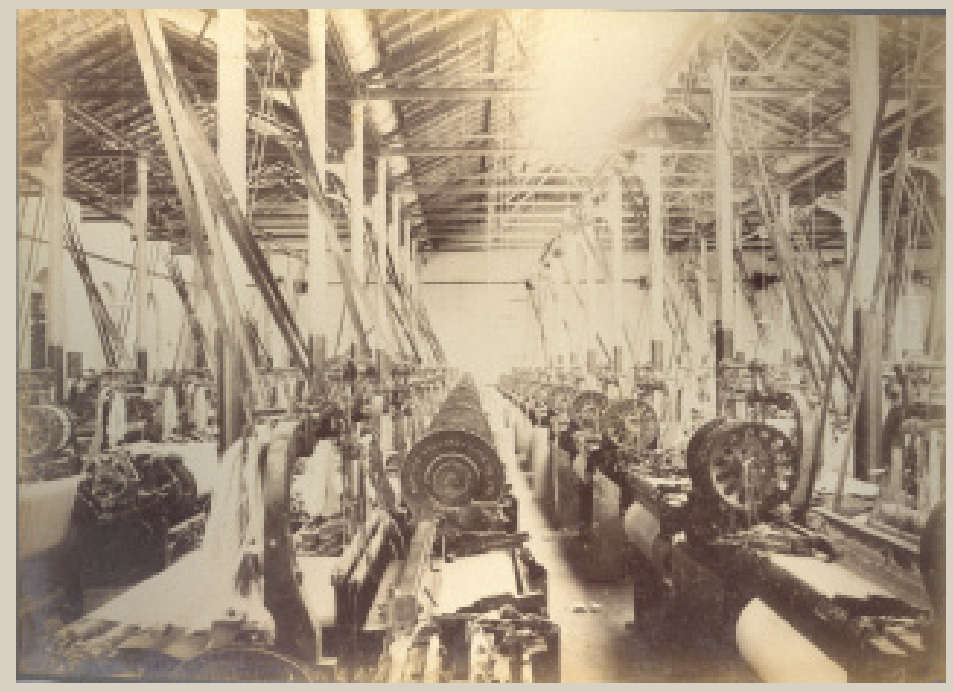

Fonte: Coleção Secretaria da Agricultura Comércio e Obras Públicas do Estado de São Paulo - Centro de Memória-Unicamp 
Evidencia-se, então, certa cenarização, o que também implicava a ruptura na rotina de trabalho, do ambiente fabril com vistas ao registro fotográfico, uma vez que as imagens tinham por objetivo dar a ver o espaço e o maquinário da fábrica, principais atores na demonstração da grandeza e do avanço tecnológico, temas centrais da obra. Ainda reforçavam um discurso de higiene e salubridade fabril, fato relevante para a divulgação da companhia, atração de mão de obra, financiadores e investimentos para os negócios.

Muitas das fotos foram dedicadas exclusivamente às máquinas, resultando em registros nos quais figuram apenas fileiras e fileiras de aparato técnico. Considerando os termos formais das imagens, pode-se observar que a maior parte das fotografias foi registrada a partir de ângulos diagonais, 0 que lhes permite mostrar o máximo possível dos espaços internos. De forma semelhante, o maquinário foi registrado em perspectiva, salientando ao observador sua dimensão, o volume dos equipamentos, ao mesmo tempo em que tornava visíveis áreas mais extensas dos mesmos. As exceções acontecem nas imagens que buscam retratar a quantidade e o volume (numérico) de máquinas comportadas em determinadas seções; nesses casos, alguns dos registros são frontais.

Pode-se inferir, assim, que as máquinas e sua disposição no interior da fábrica são as figuras centrais do álbum, com destaque para os motores elétricos, fotografados com enquadramento e linguagem próxima à tradição dos retratos de pessoas. Tal destaque dado ao motor pode ser explicado por sua centralidade no contexto tecnológico do período, no qual praticamente todo o maquinário de uma fábrica era movido mecanicamente pelo mesmo eixo, conectado às máquinas a partir do teto por engrenagens e correias. Esse eixo, por sua vez, ligava-se ao motor, que distribuía sua potência às demais máquinas, o que também explica as muitas salas entrecortadas por barras metálicas e correias apresentadas nas fotografias do álbum, assim como o registro da potência dos motores de cada uma das fábricas nas descrições trazidas pelo folheto anexo.

Além dos motores e do próprio Francisco Matarazzo, o engenheiro ou técnico da fábrica de fósforos, que muitas vezes se
Imagem 5-Fiação e Tecelagem "Mariangela"-Motor de funccionamento (entre 1904 e 1906) tornava o responsável por sua administração, também é retratado de forma individual, mas ao lado das máquinas. Esse protocolo de representação, comum na linguagem fotográfica do período, concede ao retratado o prestígio da individualização na imagem além de demonstrar sua importância hierárquica e refinamento intelectual. 


\section{Dossiê}

Imagem 6-Fabrica de Phosphoros "Sol Levante" Serra de madeira (entre 1904 e 1906)

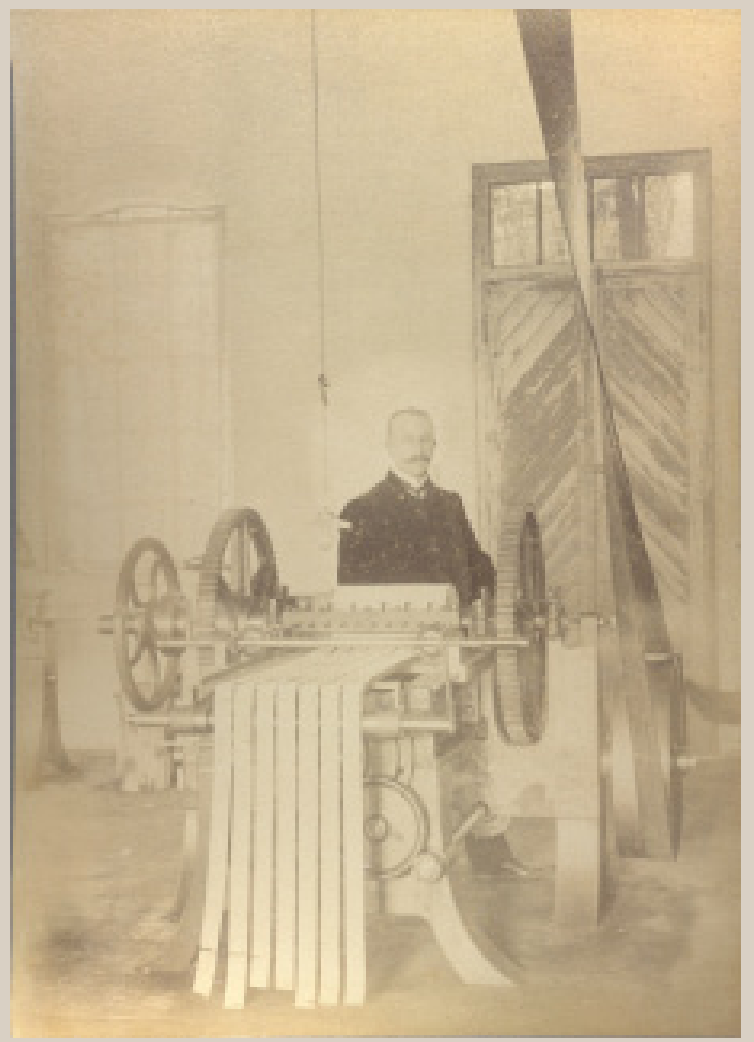

Fonte: Coleção Secretaria da Agricultura Comércio e Obras Públicas do Estado de São Paulo - Centro de Memória-Unicamp

Imagem 7-Fiação e Tecelagem "Mariangela"-Pessoal ajudante (entre 1904 e 1906)

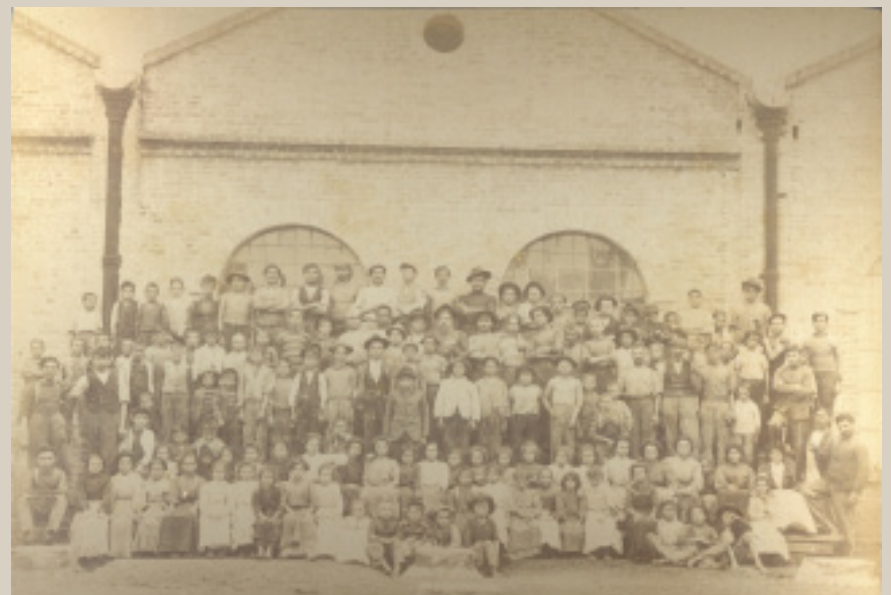

Fonte: Coleção Secretaria da Agricultura Comércio e Obras Públicas do Estado de São Paulo - Centro de Memória-Unicamp
No que diz respeito à representação da mão de obra, não há trabalhadores dentro do espaço fabril em três quartos do álbum. Nas grandes fábricas, eles foram retratados a partir de um ângulo frontal e reunidos de maneira a acentuar sua grande quantidade, como nas imagens de fileiras de equipamentos. As fotos desses grupos numerosos foram registradas do lado de fora, geralmente acomodados em estruturas de madeira improvisadas. A única exceção refere-se aos trabalhadores mecânicos do Moinho Matarazzo, que aparecem dentro do local de trabalho, o que pode ser atribuído ao fato de ser esta a seção transformada em metalúrgica para a fabricação de embalagens para a banha, como já mencionado. Tal separação garantiria, assim, sua diferenciação dos demais funcionários, ao mesmo tempo em que retrataria o ambiente da metalúrgica, possivelmentejá em projeto.
Imagem 8-Moinho Matarazzo-
Pessoal Mechanico (entre 1904 e 1906)

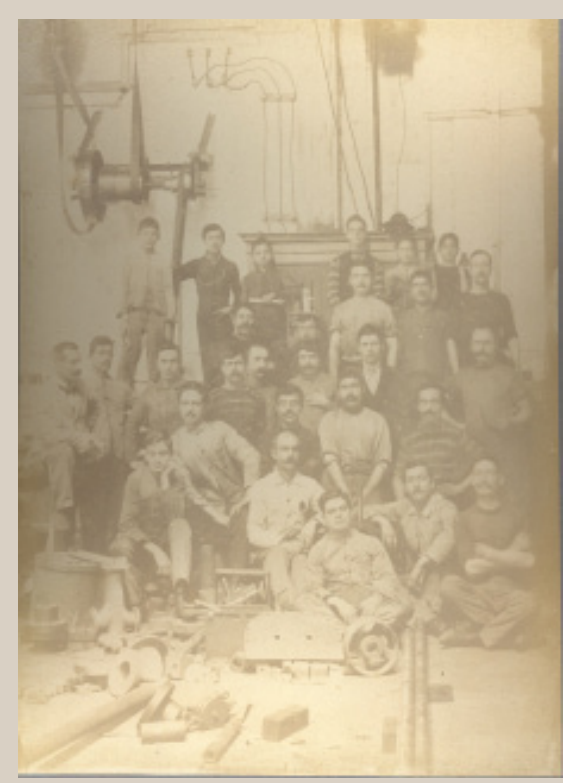

Fonte: Coleção Secretaria da Agricultura Comércio e Obras Públicas do Estado de São Paulo-Centro de Memória-Unicamp 
O motivo pelo qual os trabalhadores foram retratados fora do espaço de produção não está ligado à falta de iluminação, visto que é possível observar que os ambientes fotografados, em geral, têm iluminação natural abundante típica de construções fabris, mas sim ao discurso da obra. Conforme já foi apontado, o discurso visual do álbum não tem como foco a atividade desenvolvida pelos operários no espaço retratado, mas sim o tamanho, organização, capacidade, modernidade do equipamento e, consequentemente, potencial de produção das empresas do grupo. Nesta ótica, os trabalhadores aparecem também como parte do potencial de produção e têm importância pelo número que simbolizam, motivo pelo qual são representados em grandes grupos, dispostos em forma de arquibancada, o que amplia o impacto visual da quantidade de funcionários.

Além disso, o "pessoal"4 da fábrica aparece dividido por gênero e função. Nas fotografias do Moinho Matarazzo, pode-se observar a separação dos trabalhadores por função (moinheiros, ensacadores, pessoal mecânico); divisão que também aparece na Fábrica de Óleo Sol Levante, na qual são fotografados em separado: o pessoal do mecânico, pessoal da refinação, pessoal do acondicionamento e carpinteiros. Nas fotografias da Fiação e Tecelagem Mariângela, temos, ainda, a separação entre tecelões, tecelãs, pessoal ajudante, tecelãs de teares Northrop, conforme as legendas do álbum. Aqui é possível observar não só a divisão de funções e de gênero dentro de uma mesma função, como também uma diferenciação por especialização dos que operam um tipo específico de tear, mais moderno e automatizado, o Northrop Loom ${ }^{5}$.

Contudo, nas fotografias das duas últimas empresas, a Fábrica de Banha A Paulista e a Fábrica de Phosphoros Sol Levante, assim como nas fotos do armazém e da frota de caminhões, os trabalhadores foram retratados em seu local de trabalho e, mesmo nas fotos exteriores, aparecem de forma menos protocolar e sem separação por função ou gênero.

Nas imagens da fábrica de Banha A Paulista, os trabalhadores não apenas aparecem dentro do espaço fabril, como também foram retratados em atividade. Cabe lembrar que este foi um dos primeiros empreendimentos de Francisco Matarazzo - durante muito tempo mantido como propriedade individual, não fazendo parte das sociedades anteriormente abertas com os irmãos - e era o menos automatizado dentre os retratados na obra. As imagens do álbum relativas ao negócio de Capão Bonito são poucas, sete, das quais três se referem a vistas internas. As demais incluem uma vista do pasto, pessoal e vistas externas.

4 No álbum do grupo Matarazzo, o termo trabalhadores não aparece nas legendas em português - utilizou-se "pessoal" -, italiano ou francês, somente em inglês tem-se um termo próximo, workers.

5 Esse tear foi inventado em 1895 e comercializado pela British Northrop Loom Co. Ltd a partir de 1902. Trata-se de maquinário de ponta para o período de produção do álbum. 


\section{Dossiê}

Imagem 9-Fabrica de Banha "A Paulista"-Acondicionamento de banha (entre 1904 e 1906)

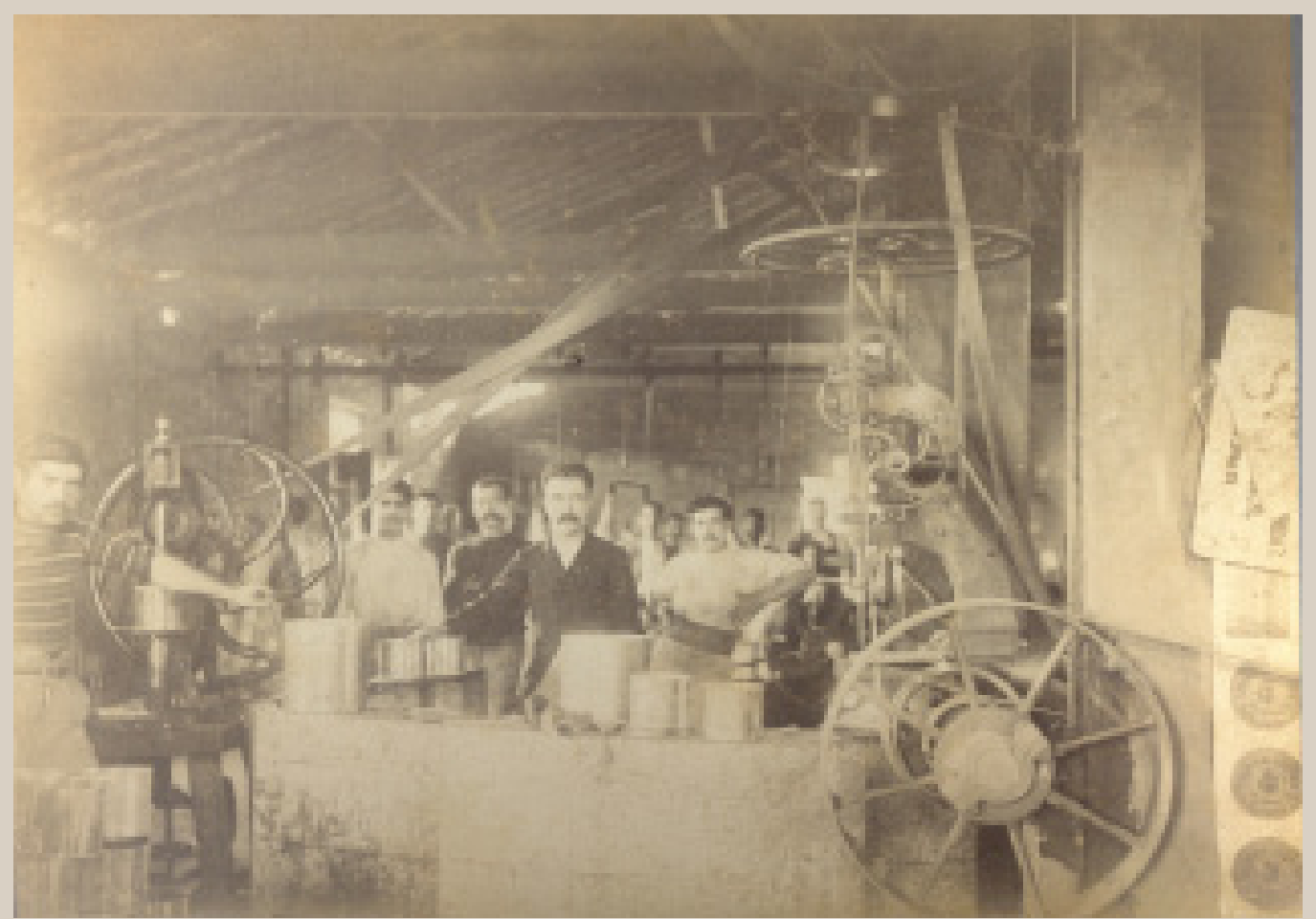

Fonte: Coleção Secretaria da Agricultura Comércio e Obras Públicas do Estado de São Paulo - Centro de Memória-Unicamp

Imagem 10-Fabrica de Banha "A Paulista" - Vista Ceral (entre 1904 e 1906)

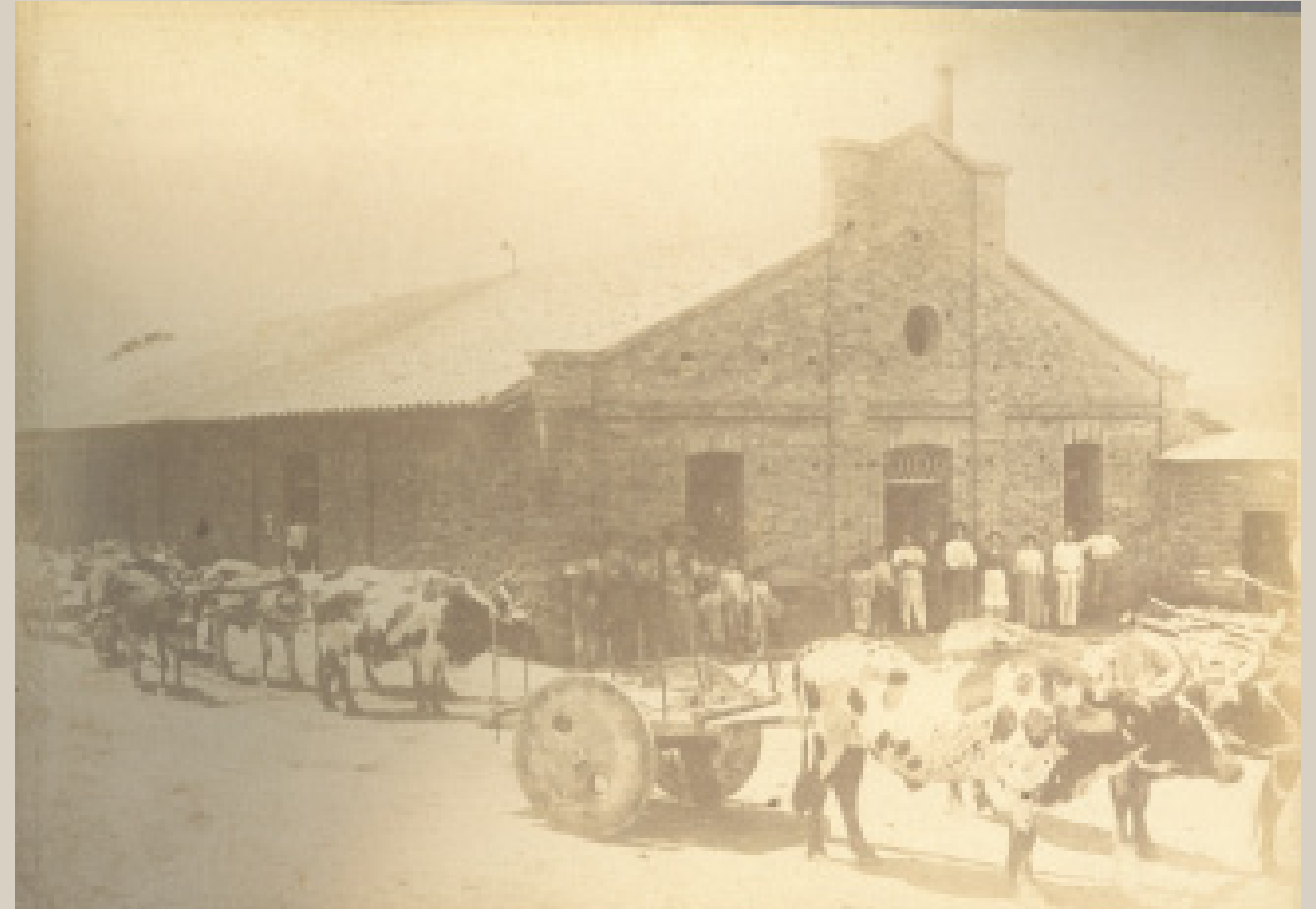

Fonte: Coleção Secretaria da Agricultura Comércio e Obras Públicas do Estado de São Paulo - Centro de Memória-Unicamp 


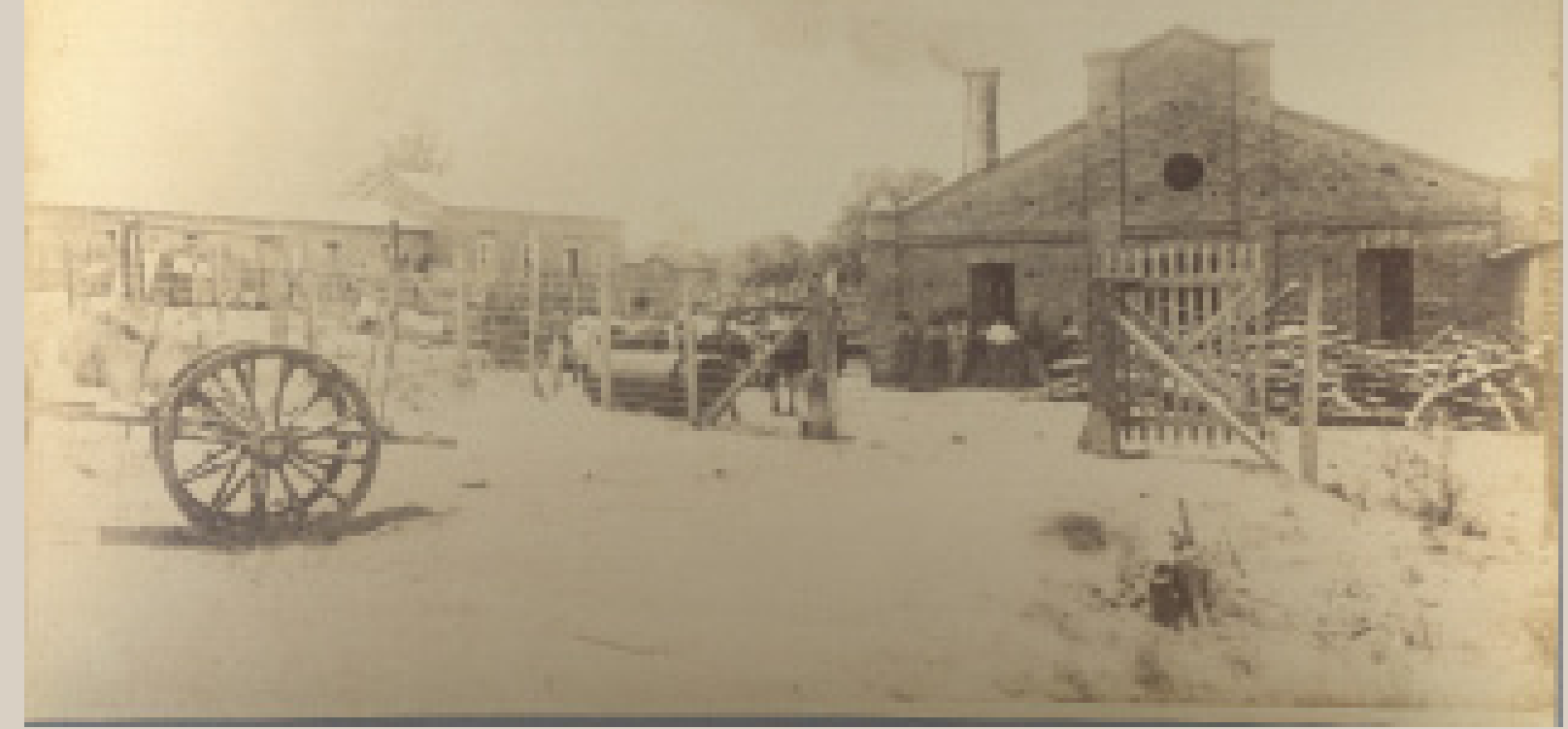

Fonte: Coleção Secretaria da Agricultura Comércio e Obras Públicas do Estado de São Paulo - Centro de Memória-Unicamp

Comparando as duas últimas fotografias do exterior do prédio, é possível admitir que nelas tenha sido acrescida artificialmente à construção uma chaminé, para garantir-lhe 0 ar fabril. Nestas imagens, também pode-se observar que os trabalhadores aparecem dentro da fábrica ou realizando as atividades para dar sentido à produção ali realizada e, ao mesmo tempo, disfarçar a rudimentaridade do espaço.

Já nas fotografias da fábrica de óleos, surge outra situação, que pode estar ligada ao fato de registrarem um menor número de trabalhadores, 65 funcionários, segundo o encarte que acompanha o álbum. É possível ver nas imagens do "pessoal" que muitos deles seguram as ferramentas utilizadas no trabalho ou que simbolizam seu ofício; em uma delas foi incluída até uma placa que sinaliza o ofício dos retratados, trabalhadores da carpintaria. Esta atitude faz referência à linguagem herdada da pintura e comum nos retratos, nos quais geralmente as pessoas são apresentadas com objetos que fazem alusão à sua profissão ou status social. Ao mesmo tempo, estabelecem diálogo com as imagens de ofícios, como aquelas feitas por 


\section{Dossiê}

Marc Ferrez e Vincenzo Pastore, no momento em que alguns dos funcionários exibem suas ferramentas de trabalho mesmo nas fotografias de grupo. Em uma delas chegam a formar um grande mise-en-scène das atividades de toda a fábrica, incluindo até mesmo os produtos finais, o que também funciona como maneira de preencher, com produtos e ferramentas, o espaço fotográfico ocupado por um número não tão extenso de operários.

Imagem 12 - Fabrica de Oleos "Sol Levante" - Pessoal do accondicionamento (entre 1904 e 1906)

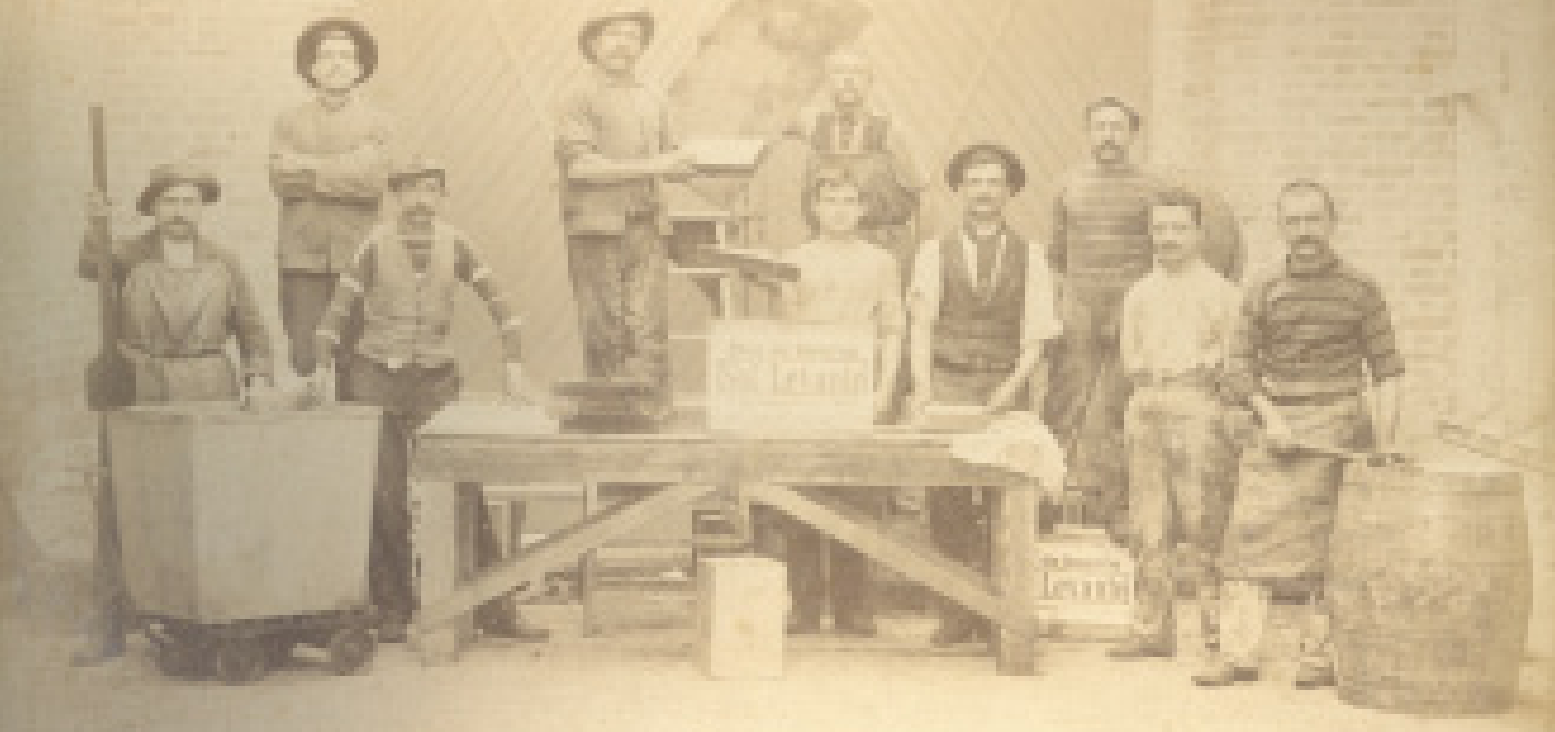

Fonte: Coleção Secretaria da Agricultura Comércio e Obras Públicas do Estado de São Paulo - Centro de Memória-Unicamp

No contexto industrial dessas fotografias - que se diferencia da maioria dos trabalhadores urbanos registrados por Ferrez e Pastore pelo fato de os trabalhadores fabris não possuírem suas próprias ferramentas de trabalho -, é possível pensar que a empunhadura destes objetos poderia significar uma tentativa de demonstrar a propriedade de um saber, um domínio de ofício, em substituição ao controle da produção. Entretanto, não é possível saber até que ponto os trabalhadores poderiam ou não ter controle sobre a montagem da cena fotográfica, que também pode ter sido originada de uma iniciativa dos produtores para atrair a atenção para atributos da produção, diante do baixo número de trabalhadores empregados nessa fábrica em comparação às demais. 
Apesar da impossibilidade de afirmar que a exibição de instrumentos de trabalho seja uma tentativa de individualização consciente por parte dos trabalhadores em meio à sua representação sempre coletiva, é possível notar algum grau de preocupação dos mesmos com sua imagem fotográfica por meio do cuidado com a própria roupa e aparência física. Em algumas das fábricas isso fica mais evidente, especialmente nas indústrias maiores e localizadas em São Paulo, como o moinho e a fiação. É possível observar na fotografia dos ensacadores e costuradores que os trajes dos trabalhadores provavelmente não são os mesmos utilizados no trabalho diário. Um exemplo é o quarto homem (da esquerda para a direita) da segunda fileira, cuja indumentária pode sugerir um desejo de enfatizar distinção em relação aos demais trabalhadores, assim como pode-se deduzir que os trajes nem mesmo pertençam a eles, como é possível considerar a partir do colete e do paletó do quarto homem (da esquerda para a direita) da primeira fileira. Os dois casos podem ser compreendidos como um esforço de construção, ainda que com limitações, de uma determinada imagem a ser perenizada por parte dos trabaIhadores fotografados.

Imagem 13-Moinho Matarazzo - Ensaccadores e costuradores (entre 1904 e 1906)

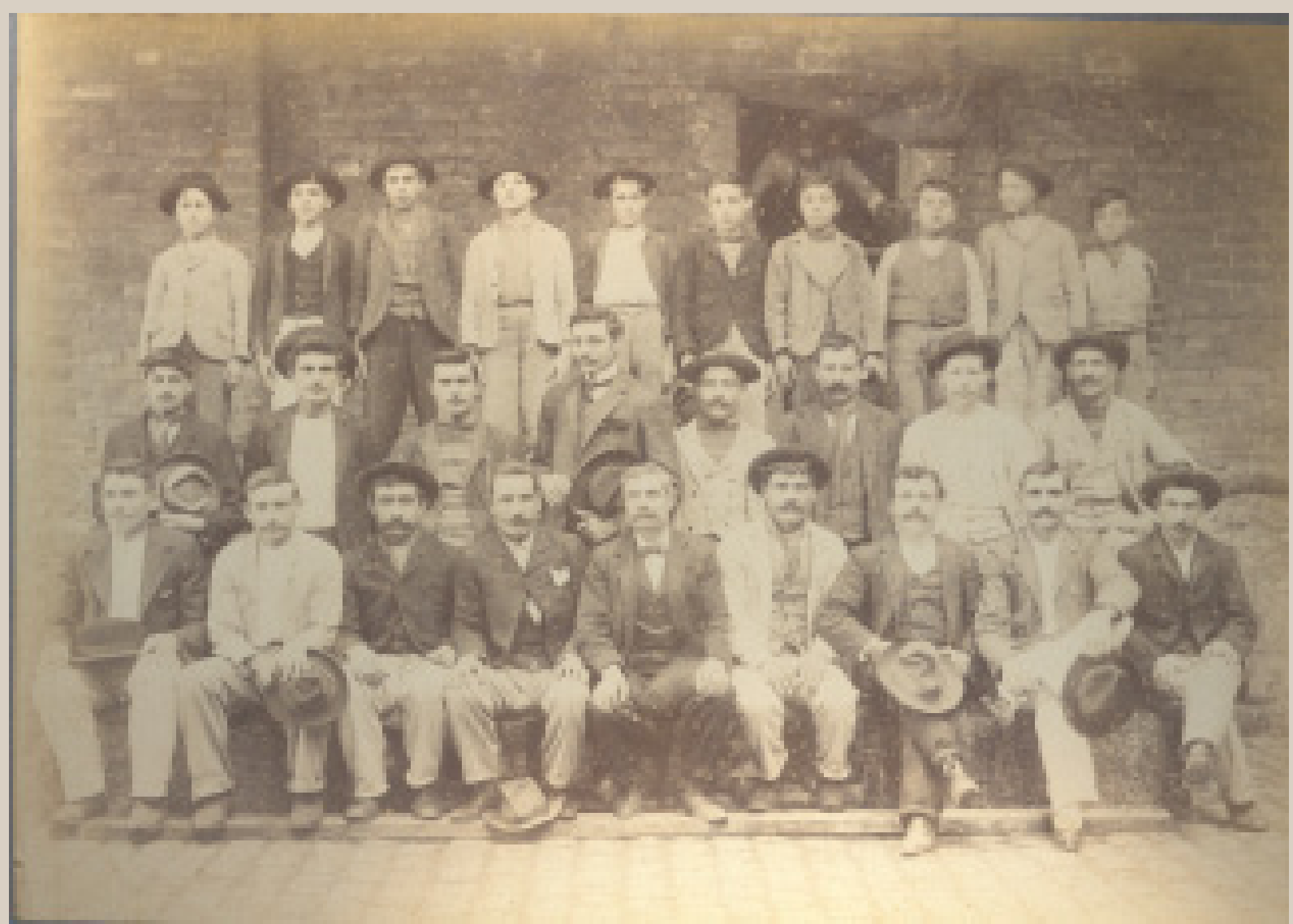

Fonte: Coleção Secretaria da Agricultura Comércio e Obras Públicas do Estado de São Paulo - Centro de Memória-Unicamp 


\section{Dossiê}

Outro ponto levantado pelas fotografias em torno da construção de um espaço de discurso dos próprios trabalhadores sobre si diz respeito às relações que estabelecem com os outros trabalhadores. Nas fotografias coletivas, pode-se observar a procura, por parte dos retratados, de estabelecer entre si contato físico, que nem sempre pode ser considerado acidental ou motivado pela falta de espaço.' Enquanto algumas das pessoas sentadas umas ao lado das outras mal se tocam, outras realizam os movimentos trabalhosos, bastante acentuados e pouco naturais para serem retratadas em ligação. Braços entrelaçados, toques nas pernas e ombros poderiam sinalizar a vontade de evidenciar uma relação que ultrapassaria a do ambiente de trabalho, possivelmente familiar. Dessa forma, também se torna possível observar redes de relações pessoais transcritas nas imagens por meio do contato físico.

Imagem 14 - Fiação e Tecelagem “Mariangela"-Tecelans (entre 1904 e 1906)

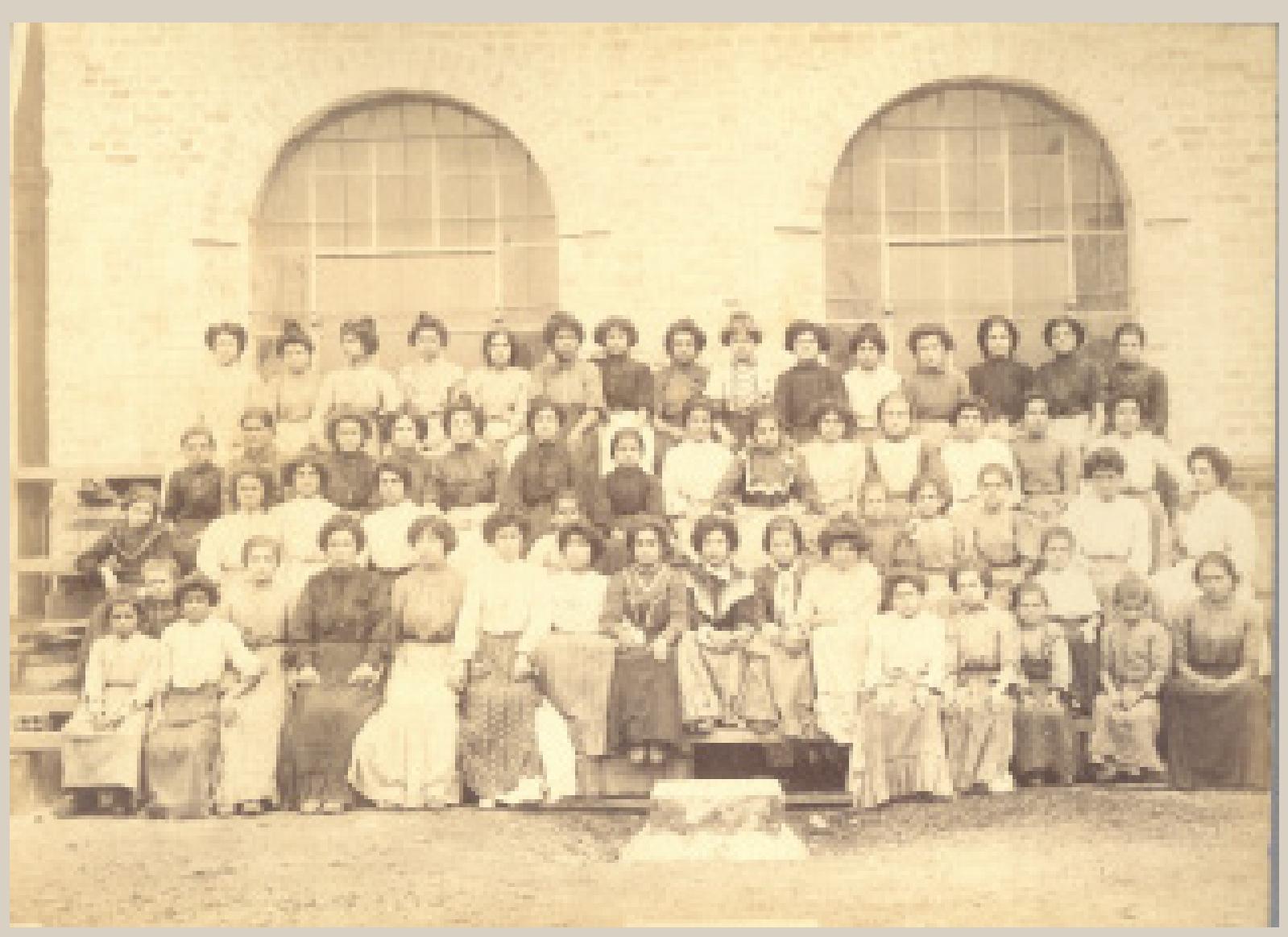

Fonte: Coleção Secretaria da Agricultura Comércio e Obras Públicas do Estado de São Paulo - Centro de Memória-Unicamp

\section{Considerações Finais}

As considerações sobre o álbum F. Matarazzo \& Cia Industriaes aqui apontadas inserem sua produção em um momento de transformação das atividades do grupo, o que acarretou a necessi- 
dade de divulgação dos negócios, bem como o detalhamento do maquinário, produção, ambiente fabril, mão de obra. Assim, obra e companhia são inseridas em um contexto de economia visual, no qual a circulação de imagens fotográficas nesse formato cuidadosamente elaborado tinha como objetivo auxiliar os processos econômicos, sociais e políticos desejados por seus produtores.

Nesse contexto, tais iniciativas eram entendidas, mais do que como um dever, como um privilégio pertencente aos industriais, cujas figuras eram vinculadas ao aparato tecnológico, aumentando seu prestígio social, político e potencializando sua atividade econômica, ao mesmo tempo que também mantinham exclusividade sobre o acesso, a representação e a produção de discursos, dentre eles o visual, acerca do ambiente de produção. Cabe observar que, nos anos posteriores, 0 Estado passa a disputar com os industriais e os empresários o acesso ao espaço privado da fábrica, e torna-se também um produtor de representações e discursos visuais em torno das diversas atividades econômicas nacionais (POMARI \& MENECUELLO, 2019).

Por fim, ainda que o foco do álbum seja o aparato industrial da Companhia Matarazzo, as imagens dos trabalhadores também ficaram registradas nas frestas desta vitrine da modernidade fabril. Personagens que provavelmente não teriam tido contato com sua imagem perpetuada e com os quais não teríamos deparado, não fosse pela iniciativa desse registro visual das indústrias da família italiana.

\section{Referências}

BARBUY, Heloísa. A exposição universal de 1889 em Paris: visão e representação na sociedade industrial. São Paulo: Loyola, 1999

BENJAMIN, Walter. Passagens. Tradução de Irene Aron/Cleonice Paes Barreto Mourão. Belo Horizonte: São Paulo: Editora UFMG/Imprensa Oficial, 2007.

COUTO, Ronaldo Costa. Matarazzo. São Paulo: Planeta, 2004. (Vol. 1)

CRARY, Jonathan. Técnicas do observador: visão e modernidade no século XIX. Rio de Janeiro: Contra-ponto, 2012.

DEAN, Warren. A industrialização de São Paulo: 1880-1945. São Paulo: DIFEL, 1971.

DEBORD, Guy. A sociedade do espetáculo: comentários sobre a sociedade do espetáculo. Rio de Janeiro: Contraponto, 1997. 
FABRIS, Annateresa (Org.) Fotografia: usos e funções no século XIX. São Paulo: EdUSP, 1991.

GELL, Alfred. Art and agency: an anthropological theory. New York: Clarendon, 1998.

HARDMAN, Francisco Foot. Trem fantasma: a modernidade na selva. São Paulo: Companhia das Letras, 1991.

KOSSOY, Bóris. Dicionário histórico-fotográfico brasileiro: fotógrafos e oficio da fotografia no Brasil (1833-1910). São Paulo: Instituto Moreira Salles, 2002.

LIMA, Solange Ferraz e CARVALHO, Vania Carneiro. Fotografia e cidade: da razão urbana à lógica de consumo: albuns de São Paulo, (1887-1954). São Paulo, Campinas. FAPESP/Mercado de Letras, 1997.

MARTINS, José de Souza. Conde Matarazzo: o empresário e a empresa, estudo de sociologia do desenvolvimento. 2. ed. São Paulo: Hucitec, 1973.

MAUAD, Ana Maria. Posese flagrantes: ensaios sobre história e fotografias. Niterói. EdUFF, 2008.

MENESES, Ulpiano Bezerra. Fontes visuais, cultura visual, história visual: balanço provisório, propostas cautelares., São Paulo, v. 23, n. 45, p. 11-36, jul. 2003.

POMARI, Elisa; MENECUELLO, Cristina. Aos homens de estado e aos homens de ciência: a produção de imagens pela secretaria de agricultura do estado de São Paulo: (1904-1914). Revista Acervo, Rio de Janeiro, v. 32, n. 2, p. 131-148, maio. 2019.

TURAZZI, Maria Inez. Poses e trejeitos; a fotografia e as exposições na era do espetáculo (1839-1889). Rio de Janeiro: Funarte/Rocco, 1995. 